\title{
Quality healthcare services under National Health Insurance Scheme in Ghana: perspectives from health policy implementers and beneficiaries
}

\author{
Daniel Dramani Kipo-Sunyehzi \\ Legon Centre for International Affairs and Diplomacy, University of Ghana, \\ Accra, Ghana
}

\begin{abstract}
Purpose - This paper aims to examine the factors that affect the quality of healthcare services in the implementation of the National Health Insurance Scheme (NHIS) at the local level in Ghana from the perspectives of health policy implementers and beneficiaries in public-private organisations.

Design/methodology/approach - This paper has adopted a mixed research method with both qualitative and quantitative data, with in-depth interviews, document analysis and focus groups discussions. A total of 107 participants took part in the interviews and the questionnaire survey.

Findings - The study found that these factors greatly affect the quality of healthcare services from the implementers' perspectives - referrals, effectiveness in monitoring, timeliness, efficiency, reimbursement, compliance with standard guidelines of Ghana Health Service (GHS) and accreditation process. For the beneficiaries, three healthcare services factors are important, including medical consultations, diagnostic services and the supply of drugs and medicines. Some other factors are found to be the least prioritized healthcare services, namely the issuance of prescription forms, verification of identification (ID) cards and staff attitude. However, the study found that implementers and beneficiaries exhibited a mixed reaction (perspectives) on accessing some healthcare services. In some healthcare services where the implementers perceived that beneficiaries have more access to such services, the beneficiaries think otherwise, an irony in the perspectives of the two actors.

Originality/value - This paper adds to the extant literature on the perspectives of policy implementers and beneficiaries on factors that affect the quality of healthcare services in general and specifically on the implementation of NHIS in Ghana with the public-private dimension.
\end{abstract}

Keywords Health facilities, Implementers, Beneficiaries, Quality healthcare services, Ghana

Paper type Research paper

HKPAA

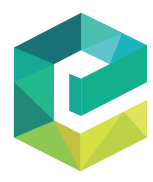

Public Administration and Policy Vol. 24 No. 3, 2021 pp. $320-332$ Emerald Publishing Limited 1727-2645 DOI 10.1108/PAP-08-2021-0047

\section{Introduction}

This paper examines the factors that affect the quality of healthcare services in the context of the implementation of the National Health Insurance Scheme (NHIS) in Ghana. The NHIS is initiated by the Government of Ghana in 2003 and implemented in 2004. It is backed by the National Health Insurance Laws and a Legislative Instrument (LI) I.1809 (Government of Ghana, 2003, 2004, 2012). The purpose of the NHIS is to "secure the provision of basic healthcare services to persons resident in the country through mutual and private health insurance schemes; to put in place a body to register, license and regulate health insurance

(C) Daniel Dramani Kipo-Sunyehzi. Published in Public Administration and Policy. Published by Emerald Publishing Limited. This article is published under the Creative Commons Attribution (CC BY 4.0) license. Anyone may reproduce, distribute, translate and create derivative works of this article (for both commercial and non-commercial purposes), subject to full attribution to the original publication and authors. The full terms of this license may be seen at http://creativecommons.org/licences/by/4.0/ legalcode 
schemes and to accredit and monitor healthcare providers operating under health insurance schemes. .." (Government of Ghana, 2003, p. 4). This provision of the law expects the National Health Insurance Authority (NHIA) to monitor healthcare providers (hospitals, clinics, and others) in the implementation of NHIS in order not to compromise the quality of healthcare services they render to health insurance beneficiaries throughout Ghana.

Also, section 68 of the National Health Insurance (NHI) Act stipulates that healthcare services that are rendered to beneficiaries should be "reasonably good quality and high standard". The healthcare service providers should use "medical technology and equipment" that is consistent with actual needs and conforms to standards of medical practice in Ghana. Moreover, the accredited healthcare service providers should follow medical procedures, administer appropriate drugs to beneficiaries and comply with the "accepted medical practice and ethics". Finally, healthcare service providers must ensure that drugs and medication used in the provision of healthcare services to beneficiaries are approved in the National Health Insurance Drug List of the Ministry of Health (Government of Ghana, 2003, pp. 16-17). These are some key provisions in the health insurance law to safeguard the provision of quality healthcare services to beneficiaries in the implementation of NHIS. To what extent are these key provisions on quality healthcare services adhered to in the implementation of NHIS is investigated in this paper. Moreover, as not many studies have examined the perspectives of implementers and beneficiaries from public-private healthcare provision, this paper attempts to fill in such gap in the implementation of NHIS.

\section{Literature review}

\section{Implementation of the NHIS and implementers and beneficiaries' perspectives on quality}

The implementation of the National Health Insurance Scheme (NHIS) started in 2004 in Ghana intending to cover all citizens and persons with legal residence in the country, which is Ghana's NHIS journey towards achieving Universal Health Coverage (UHC). Several studies show the NHIS covered about 40 percent of the population while 60 percent are yet to be enrolled into the scheme (Nketiah-Amponsah et al., 2019; Kipo-Sunyehzi et al., 2019; Umar et al., 2020; Kipo-Sunyehzi, 2020). There are reasons for such a rate of population coverage of the NHIS, one of which is the access to quality healthcare services. The literature points out that the better the quality of healthcare services, the more the enrolment into NHIS as improving quality healthcare services will enhance the full benefits of the NHIS (KipoSunyehzi, 2020; Ekholuenetale and Barrow, 2021).

Several studies have been conducted on the implementation of NHIS in Ghana on the quality of services offered to the insured (NHIS beneficiaries) and uninsured (those who pay cash-out of pockets) patients. These studies found some unequal treatment between the insured and uninsured patients in terms of the quality of healthcare services offered to them. These studies suggest that implementers of NHIS (health service providers) tend to exhibit more negative attitudes towards the insured than the uninsured at health facilities. Thus, the insured experienced more shouts, verbal abuses, spent longer waiting time (hours at facilities), and tend to suffer from different forms of discrimination during healthcare service delivery. The beneficiaries attributed these negative attitudes towards them to their lack of cash payments for the healthcare services (Kipo-Sunyehzi, 2020; Umar et al., 2020).

Moreover, there is a significant difference between the insured and the uninsured patients in Ghana in terms of financial access to healthcare services. The literature shows the insured still pay cash at the point of service delivery (out of pocket payments) though the uninsured bear more financial cost compared with the insured. Thus, there are several inequalities in terms of out-of-pocket payments or expenditure for healthcare services utilisation under NHIS. Some implementation challenges include the inability of the insured to determine which healthcare services are covered under NHIS and those that are not covered. Women of 
reproductive ages are also at risk of out-of-pocket payments or expenditure. Yet many beneficiaries look happy for NHIS in terms of the less financial burden on payments of medical bills. Also, under NHIS, pregnant women are exempted from premium payments and they have free access to antennal, skilled delivery and postnatal healthcare services. Studies show that pregnant women have more access to healthcare services under NHIS. The empirical evidence shows that about 78.2 percent of pregnant women indicated that NHIS is helping them in accessing maternal healthcare services in Ghana. Thus, the free maternal health policy has a positive effect on NHIS enrolment (Agbanyo, 2020; Okoroh et al., 2020; Umar et al., 2020; Ekholuenetale and Barrow, 2021). Despite this positive aspect of NHIS, other studies identified some challenges including distance travel to accredited health facilities, travel cost and perceived poor quality of healthcare services rendered to NHIS beneficiaries (Kodom et al., 2019; Ameyaw et al., 2021).

Several studies examine the perspectives of the health policy (NHIS) beneficiaries on the quality of healthcare services at credentialed health facilities in the implementation of NHIS in Ghana. These studies report beneficiaries' dissatisfaction with the quality of healthcare services. Some of the beneficiaries report cheap drugs and medicines, extra payments for expensive drugs/medicines, shortages of drugs, less attention from service providers at facilities, among others. (Atinga, 2012; Nketiah-Amponsah et al., 2019; Ampaw, et al., 2020).

The implementation of NHIS is also examined from the perspectives of implementers or the health service providers on factors that affect the quality of healthcare services. Some factors identified include delays in the submission of claims, the processing of claims and the reimbursement of claims, inadequately qualified staff, and the incidence of reused disposable medical supplies. Other factors identified to affect quality healthcare services include a shortage in supply of drugs/medicines, low morals of service providers, which in turn affect the quantity and the quality of services provided to NHIS beneficiaries. On the other hand, health insurance managers/officials expect service providers' strict compliance with tariffs and the use of appropriate referrals to help deal with delays in the processing of claims and reimbursement. Other challenges on NHIS identified by some service providers include how to effectively deal with corruption and intense political influence (Andoh-Adjei et al., 2018; Kipo-Sunyehzi, 2018; Christmals and Aidam, 2020; Akweongo et al., 2021).

Despite these studies on the implementation of Ghana's NHIS, not many have been conducted on the perspectives of both implementers and beneficiaries from the lens of publicprivate provision of healthcare services. In this regard, this paper attempts to bridge the literature gap with a specific focus on the perspectives of NHIS implementers and beneficiaries on the factors that affect quality healthcare services in Ghana with a publicprivate dimension.

\section{Quality healthcare service dimensions and perspectives on Ghana's health insurance scheme}

There is no universally accepted definition of quality healthcare as there are diverse perspectives. Donabedian (1990) gives an elaboration of quality healthcare service on six relevant areas for physicians: (1) Efficacy - the ability of the healthcare system to improve health; (2) Effectiveness - the degree of attaining healthcare objectives or goals; (3) Efficiency attaining or obtaining the greatest health improvement at the lowest cost, thus balancing health costs and benefits; (4) Acceptability - meeting patients or customers preferences in most/all aspects of health delivery; (5) Legitimacy - conformity to societal tastes or preferences; and (6) Equality - fair access and fair distribution of health care resources.

Quality healthcare services can be defined in terms of 'conformance quality' which means meeting requirements such as accreditation of health service providers or certification/ licensing (Penneys, 1997, p. 503). Shengelia et al. (2005) emphasised the delivery of 'highquality healthcare services to achieve 'health gains'. Thus, they stressed that 'quality' must capture the following issues or aspects: making the right diagnosis when individual/patient 
presents symptoms, choosing the most 'appropriate intervention strategy' and executing the intervention in line with 'appropriate clinical standards' (Shengelia et al., 2005, p. 99). From these conceptions, quality healthcare services can be viewed from two actors, namely clients and health service providers (workers) perspectives.

Quality healthcare services are examined in the context of the quality of emergency care (Okoroh et al., 2020) as well as the quality of maternal and childcare delivery (Atinga et al., 2018). Others focus on the quality of clinical care for the elderly (Lilleheie et al., 2020). The World Health Organisation (2018) looks at quality healthcare from six dimensions: when the service is effective, efficient, patient-centred, integrated, equitable and safe for the people.

Quality healthcare services can also be measured from the level of provider compliance with clinical guidelines (Heiby, 2014). This conception of compliance can be linked to Ghana's treatment guidelines. Ghana's standard treatment guidelines have been prepared as a tool to assist and guide prescribers (medical doctors, medical assistants/midwives), dispensers, pharmacists and other healthcare staff at primary health facilities to provide quality healthcare services to their patients. Prescribers are to follow those guidelines in the delivery of healthcare services in Ghana. The treatment guidelines serve as a reference book, which guides on treatment choices, management of patients and referrals. Patients are referred from one health facility to another when a prescriber is not able to handle or manage the patient either for lack of personal experience or availability of appropriate facilities to handle the patient case properly (Ministry of Health, 2017). The welfare of patients should be an important goal of referrals including emergency cases. Moreover, health service providers to comply with Section 68 on quality assurance in the delivery of good quality and high standard services, to use proper medical equipment, to follow medical procedures on the administration of drugs and the use of drugs based on National Health Insurance Drug List of Ministry of Health of Ghana are crucial in the implementation of NHIS (Ministry of Health, 2017).

The aim of this paper is to examine the factors that affect quality healthcare services from the perspectives of implementers and beneficiaries in public-private healthcare provision. Thus, the research question is: What factors affect the quality of healthcare services in the implementation of NHIS from the perspectives of implementers and beneficiaries?

\section{Research methodology \\ Research design}

The research design is based on mixed method approach that incorporated multiple actors' perspectives. Both quantitative and qualitative methods have been adopted based on various sources of data, including in-depth interviews, focus groups discussions, documents, census figures, and etc. so that the data can be compared for their convergence and/or divergence. The rationale of using mixed method is to take advantage of their strengths and minimise their weaknesses. The quantitative and qualitative methods are towards complementarity of the two for a better understanding of social phenomena like quality healthcare services from health service providers and users' perspectives (Baran, 2020).

Several studies have been conducted on healthcare or health services research with mixed methods in a single study or series of studies, despite some challenges in the combination which may be in data collection, analysis or interpretation. Mixed methods studies remain crucial and relevant for health researchers and clinicians in studies within or across hospitals, some looking at multi-service or multiple health service delivery areas (Fetters and MolinaAzorin, 2020).

\section{Study setting, participants and sample}

This research was carried out in the Tamale Metropolis of Ghana as it is the biggest city and the only metropolis in Northern Ghana, with an estimated population of 281,619 in 2020 
PAP

24,3

324

(Ghana Statistical Service, 2020). It was selected as it has the large number of accredited or credentialed health facilities in the implementation of NHIS, with 17 accredited or credentialed public health facilities and 38 private health facilities (National Health Insurance Authority, 2014).

The data collection took 12 months and in three phases with 2 months in 2012, 6 months in 2013 and 4 months in 2014, which ended in October 2014. The study involved four health facilities including two hospitals and two clinics along with the public-private basis and district and regional NHIA offices. The recruitment of participants was done purposively based on convenience, proximity and as insured and persons directly involved in the implementation of NHIS at health facilities and health insurance offices. The purposive sampling technique was used for two actors - NHIS beneficiaries and implementers at the selected health facilities, offices, and communities while the snowball sampling method helped more in tracing other beneficiaries. The selection or recruitment of the implementers was based on their positions at the health facilities and offices and their knowledge on NHIS, whereas the beneficiaries were recruited based on their categories: exempt group members, premium payees and contributors based on NHIS laws/regulations and other studies (Government of Ghana, 2003; 2004; 2012; Creswell, 2014; Kipo-Sunyehzi, 2020). It is important to note uninsured persons and workers who were not involved in NHIS were excluded. The number of implementers and beneficiaries who took part in the study were 107 as shown in Table 1.

\section{Instruments}

The first phase of the research involved some pilot tests and familiarisation of study sites and seeking institutional permission. Some questionnaires (close-ended questions) were administered alongside an interview guide for qualitative data. The interview guide (openended questions) was used during in-depth interviews and focus groups discussions (FGDs). All FGDs involved only beneficiaries. Four FGDs took place at hospitals and clinics $(n=24)$ and three FGDs took place at some selected communities: Kalpohin Estate, Moshie-Zongo, Lamashegu $(n=18)$. The selection of the communities or locations was based on census figures along with the geographic location (suburbs of Tamale) and socio-economic characteristics or conditions (low, middle, high income) and population of the communities (Ghana Statistical Service, 2012; 2014).

\section{Data analysis}

The interviews were digitally recorded with the permission of the participants. The audio recorded information was transcribed, field notes were typed out and meaning was made from the information. Verification of the transcripts was done by listening to the recorded information for accuracy. The open-ended questions were analysed along with themes/

\begin{tabular}{lccccccr}
\hline \multicolumn{7}{c}{ Units and Number of Participant } \\
Groups & SDA H. & W. H & HA C. & BH C. & NHIA Offices & Others & Total \\
\hline Implementers & I (7) & I (6) & I (6) & I (7) & I (4) & I (7) & $\mathbf{3 7}$ \\
Beneficiaries & I (5) & I (5) & I (6) & I (7) & I (5) & F (18) & $\mathbf{7 0}$ \\
Total & F (6) & F (6) & F (5) & F (7) & & & \\
& 18 & 17 & 17 & 21 & 9 & 25 & $\mathbf{1 0 7}$
\end{tabular}

Table 1. Participants of the study
Notes: I - In-depth interviews participants; F - Focus groups discussions participants; SDA H. -Seventh Day Adventist Hospital; W. H. - West Hospital; HA C. - Haj Adams Clinic; BH C. - Bilpeila Health Centre; NHIA National Health Insurance Authority. 
perspectives based on the participants' experiences/statements (Creswell, 2014). Thematic analysis was conducted in the study. The five steps of compiling, disassembling, reassembling, interpreting, and concluding were followed, including transcribing, grouping, or coding (similarities/differences in data), forming thematic hierarchies and matrices, making meaning out of data and drawing conclusions from the data, respectively (Castleberry and Nolen, 2018). Two major themes emerged from data such as access to healthcare services and quality healthcare services, and the presentation of findings were largely on them, and preferences which were ranked. Coding was done using qualitative data analysis NVivo software (version 10).

\section{Ethical approvals}

Approvals have been obtained from the Metropolitan Health Directorate of the Ghana Health Service and the National Health Insurance Authority (NHIA) offices (regional and district). Also, the informed consent of participants was sought for through writing or verbal communication before interviews commenced. Participation was voluntary, and other issues of privacy, confidentiality, anonymity among others were strictly adhered to (Castleberry and Nolen, 2018; Baran, 2020).

\section{Results}

Perspectives of implementers on factors that affect quality healthcare services

The views or perspectives of health policy implementers on the quality of healthcare services to health insurance beneficiaries are presented. Some factors they perceived which affect the quality of healthcare services are shown in Table 2 which include referrals, effectiveness in monitoring, timeliness, efficiency, reimbursement, compliance with standard guidelines of Ghana Health Service (GHS), and accreditation process.

Other factors mentioned by the implementers include administration of the tariff system, the state of medical equipment in health facilities including laboratories, the caseload of health workers, doing the right thing, the right time, waiting times (time beneficiaries spent at facilities), the work environment, efficacious services and meeting the health needs and the satisfaction of subscribers.

\section{Implementers' perceptions on access to quality healthcare services at health facilities}

As shown in Table 1, 26 health workers of the four selected health facilities (two hospitals and two clinics) were interviewed on NHIS beneficiaries' access to quality healthcare services at health facilities. The implementers' responses are presented in Table 3.

The healthcare service that most implementers perceived that the beneficiaries have more access to is on medical consultations (88.5 percent) while the least perceived healthcare service is on medical emergencies (46.1 percent).

\section{Beneficiaries' perceptions on access to quality healthcare services at health facilities}

Data based on beneficiaries' perceptions and opinions on access to healthcare services at health facilities, both in-depth interviews and FGDs indicated that beneficiaries have access to healthcare services such as medical consultations, the supply of drugs and medicines, diagnostic services (laboratory/ultra-scan tests, x-rays) among others. However, it was found that beneficiaries lacked knowledge on which services were of good quality, which drug or medicine, an injection was more effective or not, and they could not determine effective treatment methods. Thus, the beneficiaries relied more on what medical officials (practitioners) at health facilities prescribe, dispense, and instruct them to do. 


\section{PAP 24,3}

Effectiveness in monitoring

Timeliness

Efficiency

Reimbursement

Compliance with standard guidelines of GHS

Accreditation process

\section{Health policy implementers perspectives}

The referral system of GHS aims to increase subscribers' and other clients' access to drugs and services and part of the process towards health facilities access and quality assurance measures (I: MHO1).

Referrals are often from a lower health facility to a higher one example from a primary facility to a secondary and a tertiary facility like TTH or Komfo Anokye or Korle Bu teaching hospitals (I: SO3).

We are not able to get full cooperation from facilities in areas of right prescriptions, early submission of claims and collection of cheques, continuous monitoring of facilities to ensure good, quality health services for subscribers are also a problem (I: SO3).

You know this clinic is not for GHS, so they do not control us, we did not obtain our license from GHS but PHMHB. What matters most is that we have a license to provide health care and we are always ready to provide quality services to our clients. We got our accreditation license from the health insurance authority, but they do not control us on what services to provide and whatnot (I: PRC2).

There is the need to reduce the time subscribers spend at our offices through our decentralised registration system, we also make efforts to pay facilities claims on time towards quality service delivery (I: SO3).

We treat patients equally whether health insurance subscribers or those who pay cash, we provide prompt services in terms of medical consultation or drug prescription, and where we cannot meet the healthcare needs of patients, we refer them to higher facilities (I: PUC2)

The health care needs of subscribers are important to us and we always try our possible best not to delay their time at the facility. Above all, we provide them with good quality services (I: PRC2)

... we do not vacate facility early as most clinics do. Moreover, the provision of quality service to subscribers is our topmost priority here (I: PRC1-5\#2)

There are too many delays in payments of claims, where you provide services to insurance members for eight months without reimbursement, how... (I: PRC13\#3)

Health insurance is good, but reimbursement is the problem. Too many delays, no payments for the whole year (from January to July). (I: PUC1-3\#1)

Health facilities work within GHS treatment guidelines be it public or private facilities to ensure that the quality of health services is not compromised (I: MHO1).

Health insurance officials are involved in periodic monitoring of facilities service delivery across the country (I: NIO1).

We receive credentials of facilities forward them to the authority for approval. NHIA accreditation body or delegated persons can make unannounced visits to inspect facilities to ensure standards are not compromised (I: SO3).

We have a strict procedure that facilities must meet for accreditation and there is no favouritism, politics, or cronyism. Some service providers when they are denied accreditation, turn to blame us on these issues instead of doing the right thing. All that is expected is for the facility to meet the basic requirements of providing at least five core areas and meet the 50\% pass mark (I: RIO1).

This is a big hospital and has been able to meet all the conditions required for accreditation. Meeting conditions spelt out by NHIA is not a problem in this facility but maintaining standards and upgrading to secondary care hospital is our priority (I: PUH1, 3\#1).

We met those conditions set for facilities and have since been accredited and have renewed many times. The goal of the hospital is to become the best hospital in the metropolis (I: PRH1, 3\#3).

Table 2.

Perspectives of implementers/health service providers
Source: Fieldwork data

Notes: I: MHO - Interviewed Metropolitan Health Management Team Officer; SO - Scheme Officer; PRC Private Clinic Officer; PUC - Public Clinic Officer; NIO - National Insurance Officer; RIO - Regional Insurance Officer; PUH - Public Hospital Officer: PRH - Private Hospital Office 
The next issue is on the beneficiaries' views on access to healthcare services at health facilities. The essence of this issue is for the beneficiaries to share their views and experiences on the kind of healthcare services they received at health facilities (hospitals and clinics) in the implementation of NHIS at the local level. The beneficiaries' perceptions are summarized in Table 4.

Beneficiaries' ranking of healthcare services at health facilities

Private Clinic (HAC). During in-depth interviews and FGDs at the private clinic, the beneficiaries were asked to rank various key areas of services in their order of importance. Under the eight-point scale with ' 8 ' as the most important healthcare service (factor), while ' 1 ' as the least important healthcare service. The findings showed that medical consultations were ranked first as the most important healthcare service. The second most important healthcare service was the supply of drugs and medicines in the implementation of NHIS. The third and fourth most important healthcare services were diagnostic services and admissions, respectively. The fifth most important service was emergency services (referrals/ambulance), followed by the sixth of prescription forms, while the least important healthcare service delivery area was the processing of ID cards and staff attitude which were jointly ranked as the seventh. This means that beneficiaries at the private clinic did not see health insurance ID card processing and staff attitudes as crucial factors in the implementation of NHIS.

Public Clinic (BC). In-depth interviews and the FGDs conducted at the public clinic have interesting findings. The result showed that the most important healthcare service area (factor) was at consultations (services received at consulting unit) as ranked the first, followed by the supply of medicine, prescription forms, processing of ID card, staff attitude, emergency services, while the least important healthcare services were admissions and diagnostic

\section{Quality healthcare services under NHIS}

\begin{tabular}{lcrr}
\hline Services & No. Quality Services & Percentage & \\
\cline { 1 - 3 } Consultations & 23 & 88.5 & \\
Supply of Drugs & 17 & 65.4 & \\
Diagnostic Services & 16 & 61.5 & Table 3. \\
Admissions & 14 & 53.8 & Responses on access to \\
Maternity & 22 & 4.6 .1 & quality healthcare \\
Emergencies & 12 & & services at health \\
Total No. of Street-level bureaucrats & $\mathbf{2 6}$ & & facilities \\
Source: Fieldwork data & & & \\
\hline
\end{tabular}

\begin{tabular}{lccc}
\hline Services & 'Yes' on access to healthcare services & Percentage & \\
\cline { 1 - 2 } Consultations & 61 & 87 & \\
Drugs and Medicines & 55 & 79 & \\
Diagnostic services & 43 & 51 & Table 4. \\
Admissions (in-patient) & 39 & 56 & Beneficiaries' \\
Emergencies & 37 & 51 & perceptions on access \\
Maternity & 36 & & to healthcare services \\
Total No. of beneficiaries & $\mathbf{7 0}$ & & at health facilities \\
Source: Fieldwork data & & &
\end{tabular}


PAP

24,3

328

services. Diagnostic services were least prioritised because the health facility laboratory was not functioning or not in full operation.

Public Hospital $(W H)$. The interviews and the six beneficiaries who took part in the FGDs also ranked the healthcare services in the order of importance based on their views or experience at health facilities (hospitals). The beneficiaries ranked medical consultations and diagnostic services jointly as the two most important factors (healthcare services). Supply of medicine and admissions were also jointly ranked as the third, emergency services as the fifth and sixth for prescription forms. Processing of ID cards and staff attitudes were ranked as the least important factors respectively.

Private Hospital (SDAH). The interview ranking of healthcare services provided at the private hospital, diagnostic services were ranked as the most important one, followed by the supply of medicines, consultations, emergency services, admissions, and staff attitude. While the least important factors were the processing of ID cards and issuance of prescription forms. These findings show that beneficiaries were mindful of what service providers delivered in each unit in hospitals and clinics. A summary of the ranking of healthcare services at facilities in order of importance by the health policy beneficiaries (health insurance subscribers) is shown in Table 5.

\section{Discussion}

The study found that the factors that affect the quality of healthcare services in the implementation of NHIS in Ghana from the perspectives of implementers are multifaceted. The implementers hold the view that an effective referral system is an essential, rigorous accreditation process coupled with good as well as periodic monitoring of health facilities healthcare services. Most of the key factors identified in the study (Table 2) seem to agree with the findings of earlier studies (Kipo-Sunyehzi, 2020; Ratcliffe et al., 2020; Akweongo et al., 2021). The implementers also indicated in the responses of their compliance with the Ministry of Health and GHS quality assurance manuals and documents in the provision of quality healthcare services (Ghana Heath Service, 2007, 2012; Ministry of Health, 2017).

The health policy beneficiaries also identified factors that affect their access to healthcare services in the implementation of NHIS at the local level. The beneficiaries mentioned factors as well as conditions that they were not happy with health service providers (implementers). These include long hours spent at health facilities to follow health insurance ID card verification process, referrals to other facilities for drugs and medicines, referrals for diagnostic services like ultrasound scan, laboratory tests, and more access to a large volume

Table 5.

Summary of beneficiaries' ranking of healthcare services in the four health facilities

\begin{tabular}{|c|c|c|c|c|}
\hline $\begin{array}{l}\text { Rankings of } \\
\text { Health Services }\end{array}$ & $\begin{array}{l}\text { Private Clinic } \\
\text { (HAC) }\end{array}$ & $\begin{array}{l}\text { Public Clinic } \\
\text { (BC) }\end{array}$ & $\begin{array}{l}\text { Public Hospital } \\
\text { (WH) }\end{array}$ & $\begin{array}{l}\text { Private Hospital } \\
\text { (SDAH) }\end{array}$ \\
\hline $1^{\text {st }}$ & Consultations & Consultations & $\begin{array}{l}\text { Consult./ } \\
\text { Diagnostic }\end{array}$ & Diagnostic \\
\hline $2^{\text {nd }}$ & Medicine & Medicine & Jointly Ranked* & Medicine \\
\hline $3^{\text {rd }}$ & Diagnostic & Prescriptions & Medicine/Admis. & Consultations \\
\hline $4^{\text {th }}$ & Admissions & Processing of ID & Jointly Ranked* & Emergency \\
\hline $5^{\text {th }}$ & Emergency & Staff Attitude & Emergency & Admissions \\
\hline $6^{\text {th }}$ & Prescriptions & Emergency & Prescriptions & Staff Attitude \\
\hline $7^{\text {th }}$ & ID Card/Staff. & Admissions & Processing of ID & Processing of ID \\
\hline $8^{\text {th }}$ & Jointly ranked* & Diagnostic & Staff Attitude & Prescriptions \\
\hline
\end{tabular}

Source: Fieldwork data (FGDs at the four health facilities)

Note: $1^{\text {st }}$ represents the most important service/factor, $8^{\text {th }}$ represents the least important service/factor; *Jointly ranked services - include ( $\left(1^{\text {st }} / 2^{\text {nd }}\right.$ and $3^{\text {rd }} / 4^{\text {th }}$ in a public hospital; $7^{\text {th }}$ and $8^{\text {th }}$ private clinic) 
of perceived cheap drugs like 'paracetamol', the issuance of prescription forms, in some cases poor attitude of health workers towards NHIS beneficiaries. The factors and conditions in the findings seem to agree with other studies (Andoh-Adjei et al., 2018; Nketiah-Amponsah, et al., 2019; Ampaw et al., 2020; Umar et al., 2020). The conceptualisation of quality healthcare services among NHIS beneficiaries was problematic. The beneficiaries focus was not on the concept of quality healthcare services, but they were mindful of how their health problems or conditions are addressed, thus their healthcare needs and satisfaction. However, most implementers at health facilities (hospitals and clinics) complained of delays in the reimbursement of their health insurance claims and that affected the quality of healthcare services.

Interestingly, perceptions of NHIS beneficiaries on their access to healthcare services at health facilities (hospitals and clinics) at the local level happened to be mixed perspectives (Table 3 and 4) and irony. For instance, the implementers' view is that beneficiaries have more access to maternity services with 84.6 percent but the beneficiaries think otherwise with a 53 percent rate of access to maternity services. The overall findings showed positive results where the beneficiaries had over 50 percent access to key healthcare services at health facilities at the local level in Ghana. This finding concurs with some recent studies on pregnant women' increased access to maternal healthcare services under NHIS in Ghana (Ameyaw et al., 2021; Ekholuenetale and Barrow, 2021).

Table 5 shows that most beneficiaries prioritised three types of healthcare service delivery areas, namely medical consultations, the supply of drugs/medicines and diagnostic services. Admissions and emergency services were perceived as the next most important factors or healthcare services while the issuance of prescription forms, verification of health insurance ID cards before accessing healthcare services and staff attitude as the least important factors or least prioritised healthcare services provided at the four health facilities (hospitals, clinics) at the local level in Ghana.

Explanation for the ranking of services is that some beneficiaries felt disappointed when they were asked to go outside of a hospital or clinic to access drugs through the issuance of prescription forms, or to undergo laboratory tests or ultrasound-scan or x-ray tests. Moreover, some beneficiaries saw the verification of ID cards process as a waste of time, thus reflected in its low ranking. Most beneficiaries did not connect staff attitude to healthcare service delivery area, hence the ranking for staff attitude is low. Between the public and private health service providers (health facilities), most of the health policy beneficiaries prefer private health facilities to their public counterparts. One key factor for this preference is their perceived good quality healthcare services in terms of meeting their health needs and satisfaction at the facility and the less use of shouts and insults at the private health facilities.

\section{Conclusion}

The study established that both implementers and beneficiaries of NHIS conceptualised quality healthcare services differently, while implementers look at it from three perspectives: patient care, facility environment and professionalism, the beneficiaries mainly look at it from patient care. It was concluded that the implementers' perspectives on the factors that affect quality healthcare services were multifaceted, and beneficiaries ranking of healthcare services as multi-dimensional. Moreover, the beneficiaries ranking of healthcare services was based on what they perceived as good in solving their healthcare needs and satisfaction at health facilities. Thus, three healthcare services were more important (highly prioritized) to the beneficiaries as medical consultations, diagnostic services, and supply of drugs/ medicines, which agree largely to the perspectives of implementers.

A possible limitation of this study is the generalisation of findings based on the sample size of 107 and the use of the purposive sampling method to include categories of NHIS 
beneficiaries. Nonetheless, the findings may have the power of transferability to locations with similar settings in other countries. Moreover, the mixed-method approach has helped minimise the bias effect of using a ranking matrix in understanding the access to quality healthcare services.

The finding of this paper will have some implications for policymakers, implementers, and beneficiaries. The results suggest that policymakers have to consider the means of achieving policy goals (resources) and make adequate resources available to policy implementers. The implementers need to consider the interest of policy beneficiaries and work towards them and for the welfare of the larger society.

\section{References}

Agbanyo, R. (2020), "Ghana's national health insurance, free maternal healthcare and facility-based delivery services", African Development Review, Vol. 32 No. 1, pp. 27-41.

Akweongo, P., Chatio, S.T., Owusu, R., Salari, P., Tedisio, F. and Aikins, M. (2021). "How does it affect service delivery under the National Health Insurance Scheme in Ghana? Health providers and insurance managers perspective on submission and reimbursement of claims", PloS ONE, Vol. 16 No. 3, pp. 1-15.

Ameyaw, E.K., Ahinkorah, B.O., Baatiema, L. and Seidu, A. (2021), "Is the National Health Insurance Scheme helping pregnant women in accessing health services? Analysis of the 2014 Ghana demographic and Health survey", BMC Pregnancy and Childbirth, Vol. 21 No. 201, pp. 1-8.

Andoh-Adjei, F.X., Nsiah-Boateng, E., Asante, F.A., Spaan, E. and van der Velden, K. (2018), "Perception of quality health care delivery under capitation payment: a cross-sectional survey of health insurance subscribers and providers in Ghana”, BMC Family Practice, Vol. 19 No. 1, pp. 1-12.

Ampaw, E.M., Chai, J., Liang, B., Tsai, S.B. and Frempong, J. (2020), "Assessment on health care service quality and patients' satisfaction in Ghana”, Kybernetes, Vol. 49 No. 12, pp. 3047-3068.

Atinga, R.A. (2012), "Healthcare quality under the National Health Insurance Scheme in Ghana: perspectives from premium holders", International Journal of Quality and Reliability Management, Vol. 29 No. 2, pp. 144-161.

Atinga, R.A., Agyepong, I.A. and Esena, R.K. (2018), “Ghana's community-based primary health care: why women and children are 'disadvantaged' by its implementation", Social Science \& Medicine, Vol. 201, pp. 27-34.

Baran, M.L. (2020), "Mixed methods research design", in Baran, M.L. and Jones, J.E. (Eds), Applied Social Science Approaches to Mixed Methods Research, pp. 26-52, IGI Global, Hershey, Pennsylvania.

Castleberry, A. and Nolen, A. (2018), "Thematic analysis of qualitative research data: is it as easy as it sounds?", Currents in Pharmacy Teaching and Learning, Vol. 10 No. 6, pp. 807-815.

Christmals, C.D. and Aidam, K. (2020), "Implementation of the National Health Insurance Scheme (NHIS) in Ghana: lessons for South Africa and low-and middle-income countries", Risk Management and Healthcare Policy, Vol. 13, pp. 1879-1904.

Creswell, J.W. (2014), Research Design: Qualitative, Quantitative and Mixed Methods Approaches (4th ed.), Sage Publications, CA.

Donabedian, A. (1990), "The seven pillars of quality", Archives of Pathology and Laboratory Medicine, Vol. 114 No. 11, pp. 1115-1118.

Ekholuenetale, M. and Barrow, A. (2021), "Inequalities in out-of-pocket health expenditure among women of reproductive age: after-effects of national health insurance scheme initiation in Ghana”, Journal of the Egyptian Public Health Association, Vol. 96 No. 1, pp. 1-14.

Fetters, M.D. and Molina-Azorin, J.F. (2020), "Utilizing a mixed methods approach for conducting interventional evaluations", Journal of Mixed Methods Research, Vol. 14 No. 2, pp. 131-144. 
Ghana Health Service (2007), Quality Assurance Strategic Plan for Ghana Health Service 2007-2011, Ghana Health Service, Accra.

Ghana Health Service (2012), Quality Assurance Manual for Tuberculosis Microscopy in Ghana. Ghana Health Service, Accra.

Ghana Statistical Service (2012), 2010 Population and Housing Census, Ghana Statistical Service, Accra.

Ghana Statistical Service (2014), 2010 Population and Housing Census: District Analytical ReportTamale Metropolis, Ghana Statistical Service, Accra.

Ghana Statistical Service (2020), 2020 Projected Population, Ghana Statistical Service, Accra.

Government of Ghana (2003), National Health Insurance Act (Act 650), Accra, Ghana.

Government of Ghana (2004), National Health Insurance Regulations (L.I.1809), Accra, Ghana.

Government of Ghana (2012), National Health Insurance Act (Act, 852), Accra, Ghana.

Heiby, J. (2014), "The use of modern quality improvement approaches to strengthen African health systems: a 5-year agenda”, International Journal for Quality in Health Care, Vol. 26 No. 2, pp. 117-123.

Kipo-Sunyehzi, D.D. (2018), "Principal-agent problems in implementation of Ghana's Health Insurance Scheme", Journal of Operations and Supply Chain Management, Vol. 11 No. 2, pp. 59-74.

Kipo-Sunyehzi, D.D. (2020), "Global social welfare and social policy debates: Ghana's Health Insurance Scheme promotion of the well-being of vulnerable groups", Journal of Social Service Research, Vol. 47 No. 3, pp. 1-15.

Kipo-Sunyehzi, D.D., Ayanore, M.A., Dzidzonu, D.K. and Yakubu, A.Y. (2019), “Ghana’s Journey towards universal health coverage: the role of the national health insurance scheme”, European Journal of Investigation in Health, Psychology and Education, Vol. 10 No. 1, pp. 94-109.

Kodom, M., Owusu, A.Y. and Kodom, P.N. (2019), "Quality healthcare service assessment under Ghana's National Health Insurance Scheme", Journal of Asian and African Studies, Vol. 54 No. 4, pp. 569-587.

Lilleheie, I., Debesay, J., Bye, A. and Bergland, A. (2020), "A qualitative study of old patients' experiences of the quality of the health services in hospital and 30 days after hospitalization", BMC Health Services Research, Vol. 20 No. 446, pp. 1-14.

Ministry of Health (2017), Standard Treatment Guidelines, $7^{\text {th }}$ Edn, Ministry of Health, Accra.

National Health Insurance Authority (2014), Accreditation Report-July 2009-December 2013, National Health Insurance Authority, Accra.

Nketiah-Amponsah, E., Alhassan, R.K., Ampaw, S. and Abuosi, A. (2019), "Subscribers' perception of quality of services provided by Ghana's National Health Insurance Scheme-what are the correlates?”, BMC Health Services Research, Vol. 19 No. 196, pp. 1-11.

Okoroh, J., Sarpong, D.O., Essoun, S., Riviello, R., Harris, H. and Weissman, J.S. (2020), "Does insurance protect individuals from catastrophic payments for surgical care? An analysis of Ghana's national health insurance scheme at Korle-Bu teaching hospital", BMC Health Services Research, Vol. 20 No. 45, pp. 1-11.

Penneys, N.S. (1997), "Quality: its definition, measurement, and applications in dermatology", Journal of the American Academy of Dermatology, Vol. 37 No. 3, pp. 503-507.

Ratcliffe, H.L., Bell, G., Awoonor-Williams, K., Bitton, A., Kim, J.H., Lipstiz, S. et al. (2020), "Towards patient-centred care in Ghana: health system responsiveness, self-rated health and experiential quality in a nationally representative survey", BMJ Open Quality, Vol. 9 No. 2, pp. 1-11.

Shengelia, B., Tandon, A., Adams, O.B. and Murray, C.J. (2005), "Access, utilization, quality, and effective coverage: an integrated conceptual framework and measurement strategy", Social Science and Medicine, Vol. 61 No. 1, pp. 97-109. 
PAP

24,3

332

Umar, S., Fusheini, A. and Ayanore, M.A. (2020), "The shared experiences of insured members and the uninsured in health care access and utilization under Ghana's national health insurance scheme: evidence from the Hohoe Municipality”, PloS ONE, Vol. 15 No. 12, pp. 1-21.

World Health Organization (2018), Handbook for National Quality Policy and Strategy: A Practical Approach for Developing Policy and Strategy to Improve Quality of Care, World Health Organization, Geneva.

\section{About the author}

Daniel Dramani Kipo-Sunyehzi is a Research Fellow at Legon Centre for International Affairs and Diplomacy, University of Ghana. He had PhD/MPhil from University of Bergen, Norway, MA/BA (First Class) from University of Ghana. He coordinates the quarterly publication of "Conflict Watch" in the Centre. His research areas are public administration and policy, health policy and systems, social policy and social welfare, United Nations SDGs, foreign policy and international politics. His latest publication is "Perspectives on public policy implementation in developing world context: the case of Ghana's Health Insurance Scheme”, Public Organization Review (2021). Daniel Dramani Kipo-Sunyehzi can be contacted at: dkipo-sunyehzi@ug.edu.gh

For instructions on how to order reprints of this article, please visit our website: www.emeraldgrouppublishing.com/licensing/reprints.htm Or contact us for further details: permissions@emeraldinsight.com 